\title{
Ser mulato em Portugal nos primórdios da época moderna ${ }^{1}$
}

\author{
Francis A. Dutra ${ }^{2}$
}

Este artigo estuda os casos de vinte e sete homens agraciados com o título de Cavaleiro das Ordens Militares Portuguesas do Cristo, Santiago e de Avis, do início do século XVII até 1731, nos quais testemunhas da investigação sobre antecedentes haviam atestado que os pais ou avós desses homens haviam sido descritos como "mulatos" e/ou descendentes de escravos africanos. Quase todos os casos envolviam pessoas que viviam em Portugal. Com apenas uma exceção, a dispensa exigida foi por "falta de qualidade" e não por "pureza de sangue". Mais de $80 \%$ dessas pessoas receberam dispensas por serem "mulatos", e se tornaram membros da Ordem de Cristo (a maioria) ou da Ordem de Santiago. Palavras-chave: Mestiçagem - hierarquias sociais - ordens militares

\section{To be a "mulato" in early modern Portugal}

Studies the cases of twenty-seven men awarded knighthoods in the Portuguese Military Orders of Christ, Santiago and Avis from the early seventeenth century to 1731, where witnesses in the background investigation had testified that the parents or grandparents of these men had been described as "mulatos" and/or descended from African slaves. Almost all the cases involved people who were living in Portugal. With one exception, the needed dispensation was for "falta de qualidade" and not for "pureza de sangue." More than $80 \%$ received dispensations for being "mulato" and became members of the Order of Christ (the majority) or the Order of Santiago.

Keywords: Interbreeding - social hierarchies - military orders

\section{Etre "mulato" au Portugal aux débuts de la modernité portugaise}

Cet article étudie les cas de vingt-sept hommes sacrés chevaliers des ordres militaires du Christ, de Santiago et de Avis, depuis le début du dix-septième siècle jusquà 1731, ou les

\footnotetext{
${ }^{1}$ Artigo recebido e aprovado para publicação em julho de 2010.

${ }^{2}$ Professor da University of California/ Santa Barbara. E-mail: dutra@history.ucsb.edu
} 
témoins de l'enquête sur leurs antécédents avaient certifié que les parents ou les grands-parents de ces hommes avaient été décrits comme des "mulatos" et/ou descendants d'esclaves africains. Dans presque tout les cas il s'agissait de personnes qui vivaient au Portugal. Avec une seule exception, la dispense nécessaire a été pour raisons de "manque de qualité" et non pas pour des raisons de "pureté du sang". Plus de $80 \%$ de ces hommes ont été dispensés du fait dêtre des "mulatos" et devinrent des membres de l'Ordre du Christ (la majorité) ou de l'Ordre de Santiago.

Mots-clé: Métissage - hiérarchies sociales - ordres militaires

O Cônego D. Lázaro Leitão Aranha (1678-1767) foi nomeado membro da Mesa da Consciência e Ordens de Portugal, no dia 23 de novembro de 1716, enquanto ainda servia como secretário da Embaixada Especial em Roma junto ao Papa Clemente XI, presidida por D. Rodrigo Anes de Sá Almeida e Meneses, $3^{\circ}$. Marquês de Fontes, $7^{\circ}$. Conde de Penaguião (e mais tarde $1^{\circ}$. Marquês de Abrantes). Leitão Aranha assumiu oficialmente o seu posto na Mesa em 1718. Pouco depois, abraçou o projeto de organizar e classificar todo o material que havia nos arquivos da Mesa da Consciência e Ordens. Como parte desse projeto, juntou todas as consultas da Mesa relativas aos resultados das investigações de antecedentes de todos aqueles a quem eram outorgados títulos de cavaleiro nas três ordens militares portuguesas de Cristo, Santiago e Avis, desde o início do século XVII até $1731 .^{3}$ Ele os organizou por "impedimentos": abaixo da idade estipulada, acima da idade estipulada, ilegitimidade, maus antecedentes, falta de informação acerca dos ancestrais dos pais e de ambos os pares de avós, pais e avós cristãos-novos, muçulmanos e gentios, antecedentes pretos e mulatos, requerimentos para ter a investigação de antecedentes no Tribunal "como patria comua," lesa-majestade etc. Sob a categoria "Mulato", ("Impedimento de mulaticia e sua dispensa"), D. Lázaro Leitão Aranha listou homens - e citou os nomes de quase todos eles - que haviam recebido títulos de cavaleiro, mas que testemunhas em suas investigações de antecedentes tinham atestado que os pais ou avós dos candidatos haviam sido descritos como "mulatos" e/ou descendentes de escravos africanos. No manuscrito que sobreviveu ao terremoto de Lisboa de 1755, os números são incompletos, terminando com 23 , mas com mais quatro além

${ }^{3}$ Manuel da Silva Castelo Branco, "Os trabalhos de D. Lázaro Leitão Aranha sobre as Três Ordens Militares: Avis, Cristo e Santiago", Isabel Cristina F. Fernandes (ed.) Ordens Militares, Guerra, Religião, Poder e Cultura, Lisboa, Edições Colibri, 1999, v.I pp. 66-67, 70. 
desses. Diversos lançamentos numerados contêm mais de um nome. Uns poucos fornecem descrições, mas não citam o nome. Diversos se referem ao mesmo indivíduo - Manuel Gonçalves Doria, o militar nascido no Brasil que foi o primeiro afrobrasileiro a se tornar um cavaleiro da Ordem de Santiago. ${ }^{4}$ Usando a lista de Leitão Aranha, este estudo examina as investigações de antecedentes dos vinte e sete homens identificáveis naquela lista ${ }^{5}$ as deliberações dos membros da Mesa da Consciência e Ordens, assim como suas recomendações ao Rei (que era o governador e administrador das três ordens militares) acerca da concessão de dispensas para o impedimento de ser "mulato." 6 Quase todos os casos envolviam pessoas nascidas em Portugal. Havia duas exceções. Um nascido no Brasil - o já mencionado Manuel Golçalves Doria - e um nascido em Angola. A questão da "pureza de sangue" ou "limpeza de sangue" só foi levantada uma vez, porque só um dos citados na lista tinha antepassados "cristãos-novos" ou muçulmanos além de descender de mulatos. ${ }^{7}$ Mais de 80.7\% (21 de 26) dos citados na lista receberam dispensa por serem "mulatos" e, em sua grande maioria, tornaram-se cavaleiros da Ordem de Cristo (18) ou da Ordem de Santiago (3).

Embora este estudo tenha como foco os mulatos, vale a pena mencionar que se tem conhecimento de que sete negros se tornaram cavaleiros nas ordens militares portuguesas. Três na Ordem de Santiago (no século XVI), três na Ordem de Cristo (todos em 1609), e um na Ordem de Avis (1580). Mas só um dos sete - João de Sá Panasco, o bobo da corte durante o reinado do Rei João III (r. 1521-1557) - descendia de escravos. ${ }^{8}$ Quatro outros negros - todos eles militares nascidos no

\footnotetext{
${ }^{4}$ Francis A. Dutra, "A Hard-Fought Struggle foi Recognition: Manuel Gonçalves Doria, First AfroBrazilian to Become a Knight of Santiago", The Americas, n. 56:1, 1999, pp. 91-113.

${ }^{5}$ Existe um vigésimo oitavo indivíduo descrito por Leitão Aranha como "mulato filho de mulata captiva a folio 81 e folio 84 e no ano de 1607" que ainda não foi identificado e, por isso, não foi incluído neste estudo.

${ }^{6}$ Biblioteca Nacional, Lisboa (citada a partir de agora como BNL), Colecção Pombalina (citada a partir de agora como CP), códice 156, folios 146-147v.

${ }^{7}$ Esta pessoa, Manuel Coelho da Franca, foi rejeitada em 1723 principalmente por ser cristão-novo, e não por estar acima da idade, por ter impedimentos pessoais não nobres junto com os pais, e uma herança mulata por parte de mãe. Portanto, ele não está incluído entre as vinte e seis pessoas de herança mulata deste estudo. A investigação de antecedentes de Manuel encontra-se no Arquivo Nacional da Torre do Tombo [citado a partir de agora como ANTT], Habilitações da Ordem de Cristo [citado a partir de agora como HOC], Letra M, Maço 40, Número 30. Ver também BNL, CP, códice 156, folios 107, 108v, e 147v.
}

${ }^{8}$ Para Santiago, ver Dutra, “A Hard-Fought Struggle," pp. 93-94. 
Brasil, descendentes de escravos - foram agraciados com títulos de cavaleiro nas ordens militares portuguesas no século XVII mas nunca os receberam. ${ }^{9}$

Há muita confusão entre os pesquisadores a respeito do conceito de "pureza de sangue". Charles R. Boxer, no seu The Portuguese Seaborn Empire, 1415-1825, observou: "Se negros, mulatos e todos os indivíduos com uma mistura de sangue africano foram durante séculos considerados como 'pessoas de sangue infecta' no império português, o mesmo se aplicou aos descendentes dos judeus..." ${ }^{10}$ Outros pesquisadores também aceitaram que a herança africana depreciava a pureza de sangue. Maria Luiza Tucci Carneiro, no seu admirável estudo sobre os judeus e cristãos-novos e o desenvolvimento do conceito de pureza de sangue na Península Ibérica e no Brasil, vai além de suas evidências quando agrupa negros, mulatos e gentios como pessoas de sangue impuro. O resultado foi uma certa confusão no que se refere à associação entre pureza de sangue e herança africana. ${ }^{11}$

As ordens militares portuguesas de Cristo, Santiago e Avis, todas com estatutos muito rígidos de pureza de sangue, não fazem menção à herança africana como sendo um impedimento. Entretanto, nos estatutos da Ordem de Avis, na seção que lista as perguntas a serem feitas às testemunhas durante as provanças - não para títulos de nobreza, mas para aqueles que desejavam ser monges - há menção à necessidade de perguntar se o candidato era descendente de um escravo (sem qualificativo) ou se ele era filho ou neto de um mulato ou de um gentio. Essas perguntas, para aqueles que desejavam tornar-se monges da Ordem de Avis, não constam nos questionários destinados aos candidatos a monges de outras ordens nem daqueles destinados aos candidatos a títulos de cavaleiro das três ordens. ${ }^{12}$ Só quando a herança africana era ligada à escravidão é que havia

\footnotetext{
${ }^{9}$ Francis A. Dutra, "Blacks and the Search for Rewards and Status in Seventeenth-Century Brazil," Proceedings of the Pacific Coast Council on Latin American Studies, n. 6, 1979, p. 25-35.

${ }^{10}$ Charles R. Boxer, The Portuguese Seaborne Empire, 1415-1825, New York, Alfred E. Knopf, 1969, p. 266.

${ }^{11}$ Maria Luiza Tucci Carneiro, Preconceito Racial em Portugal e Brasil Colônia. Os Cristãos-Novos e o Mito da Pureza de Sangue, 3a. Ed., São Paulo, Perspectiva, 2005, pp. 50 e 53.

${ }^{12}$ Os estatutos das três ordens militares para o início do século XVII (e eles não mudam em edições posteriores) foram convenientemente reimpressos em José Justino de Andrade e Silva, Collecção Chronologica da Legislação Portugueza, 10 vols. (Lisboa, 1854-1859). Os da Ordem de Cristo encontram-se no vol. III, p. 181-271; os de Avis encontram-se no vol. III, pp. 272-408. Santiago encontra-se no vol. IV, pp. 1-66. As perguntas a serem feitas às testemunhas durante a investigação de antecedentes daqueles que desejavam tornar-se monges encontram-se no vol. III, p. 333:
} 
um problema, porque escravidão significava trabalho manual e trabalho manual significava "falta de qualidade".

Quando o Mestre de Campo Domingos Rodrigues Carneiro, o Pernambucano Preto, ex-escravo e alfaiate, tentou receber o título de cavaleiro da Ordem de São Bento de Avis que lhe havia sido concedido em fins do século XVII ou no começo do XVIII, enfatizara possuir a exigida "pureza de sangue" - não contaminado por judeus, muçulmanos ou outra "raça infecta". Embora os membros da Mesa da Consciência e Ordens tivessem preconceito contra ele, nenhum deles contestou a afirmação de que tinha a necessária "pureza de sangue". ${ }^{13}$

É preciso distinguir dois importantes conceitos: "Limpeza ou Pureza de sangue" e "qualidade." A dispensa da "limpeza de sangue" quase sempre envolvia o papado. "Falta de qualidade" significava falta da necessária nobreza e incluía atividade artesanal ou trabalho manual (por parte do candidato, seus pais e os dois pares de avós) não importa qual fosse o antecedente racial. Embora fosse um impedimento, falta de qualidade era facilmente dispensada pelo Rei, especialmente se os serviços que estivessem sendo recompensados fossem importantes. Como os membros da Mesa da Consciência e Ordens observaram, em 1693, no caso de Manuel Nogueira de Sousa: “[...] constou que em sua pessoa concorrem as partes pessoais e a limpeza necessaria, mas por tambem constar que seus avos paternos forao mecanicos, sendo o avô mulato [que tinha sido capturado pelos ingleses em Surrate e levado para a Inglaterra onde morreu ao chegar]" ${ }^{14}$ Três anos antes, no caso de Matias Vidal de Negreiros, que em 1690 recebeu uma dispensa por causa dos seus serviços militares, foi revelado que ele era ilegítimo. Além disso, seus avós foram descritos como "mecânicos" porque "eram descen-

\footnotetext{
"Capítulo IX: Das testemunhas, e interrogatorios das inquerições dos Freires"; Maria Luiza Tucci Carneiro, Preconceito Racial em Portugal e Brasil Colônia. Os cristãos-novos e o mito da pureza de sangue, São Paulo: Perspectiva, 2005, em seu quadro intitulado "As Ordens Militares e as Qualidades que Deveriam Ter Seus Membros Conforme Seus Estatutos” pp. 115-116, toma liberdades em sua explicação ao declarar "sem descendência de negro cativo ou de mulato". A palavra negro não está nos estatutos originais.

${ }^{13}$ Francis A. Dutra, "African Heritage and the Portuguese Military Orders in Seventeenth and Early Eighteenth-Century Brazil: The Case of Mestre de Campo Domingos Rodrigues Carneiro", Colonial Latin American Historical Review, 15:2, Primavera de 2006, pp. 113-141.

${ }^{14}$ ANTT, HOC, Letra M, Maço 44, Número 5. Ver também BNL, CP, códice 156, folios 147 e 297v. Para as cartas, datadas de 15 de novembro de 1693, autorizando as cerimônias de outorga do título de cavaleiro, ver ANTT, COC, livro 30, folios 286v-287.
} 
dentes de mulatos." ${ }^{15}$ Ao mesmo tempo, Manuel Fernandes Fogueira, um sobrinho de um cavaleiro da Ordem de Cristo, também descendente de mulatos a ser tratado mais adiante, capitão da infantaria que servia no presídio de Mombasa no leste da África, foi descrito pela Mesa como possuindo o requisito pureza de sangue, mas não tendo "qualidade" por parte de si mesmo, do pai, da mãe e do avô materno, uma vez que todos tinham trabalhado em troca de pagamento diário, de sua avó materna, que era padeira, e porque, por parte de mãe, ele tinha a "raça de mulato." "Constou ter a limpeza de sangue que se requere porem lhe falta a qualidade por ele e seu pai e mai e avô materno haverem sido trabalhadores de jornal e sua avó materna padeira. De mais de ter raça de mulato por parte de sua mai." Inicialmente, eles foram contra a dispensa, mas como ele era um capitão servindo na Índia e por causa dos serviços prestados por seu tio, ao receber o apelo, a Mesa recomendou a dispensa e o Rei aprovou. Entretanto, não há evidências nos registros da Ordem de Cristo que ele tenha recebido autorização para se tornar cavaleiro daquela Ordem. ${ }^{16}$

Vamos examinar agora alguns outros homens na lista do Cônego Leitão Aranha que tiveram o impedimento de "ser um mulato".

Um dos nomes mais antigos na lista de Leitão Aranha era o de Francisco de Azevedo Coutinho, em 1608. Ele tinha sido agraciado cavaleiro da Ordem de Cristo e um padrão de tença de $20 \$$, com o hábito devido a doze anos e meio de serviço no norte da África, especialmente Mazagão "com armas e cavalo agineta encubertado e a servir de capitão de gente de cavalo de hum das jornadas de campo". ${ }^{17}$ No dia 8 de fevereiro de 1608, a Mesa da Consciência e Ordens inicialmente negou-lhe o título de cavaleiro, com base no fato de ele ser filho bastardo de uma mulata. ${ }^{18}$ Entretanto, pouco mais de dois meses depois, ele recebeu uma carta de hábito da Ordem de Cristo, que foi dispensada sem nenhuma menção ao fato de ser mulato. Conforme descrito na sua carta de hábito, ele recebeu permissão para se tornar cavaleiro da Ordem de Cristo "sem embargo de ser filho

${ }^{15} \mathrm{BNL}, \mathrm{CP}$, códice 156, folio 146v. As cartas, datadas de 19 de janeiro de 1691, autorizando a entrada na Ordem de Cristo, encontram-se em ANTT, COC, livro 52, folios 63-63v.

${ }^{16}$ ANTT, HOC, Letra M, Maço 41, Número 21; BNL, CP, códice 156, folios 189v e 293v.

${ }^{17}$ Ver padrão de tença de 20 \$ com o hábito, 12 de junho de 1608, ANTT, COC, livro 17, folios $164-65 \mathrm{v}$.

${ }^{18}$ BNL, CP, códice 156, folio 146. 
natural e gerasão de maquanico por parte de sua mai". ${ }^{19}$ A cerimônia de outorga do título de nobreza aconteceu naquele mesmo ano. ${ }^{20}$ No ano seguinte, agora identificado como um "Fidalgo da Casa Real", Francisco de Azevedo Coutinho recebeu autorização para ter as cerimônias de asseveração realizadas na sede da Ordem em Tomar e um "alvará de promessa de uma comenda de 100\$”. No dia 13 de março de 1610, ele obteve permissão para que as mesmas cerimônias fossem realizadas em Mazagão. ${ }^{21}$

A maioria dos nomes na lista de Leitão Aranha que receberam dispensa por causa de impedimentos por serem mulatos se tornaram cavaleiros de ordens militares no final do século XVII e no início do século XVIII. Mas diversos casos interessantes ocorreram antes de 1660.

Houve dois casos importantes na Ordem de Santiago. Ambos envolveram homens nascidos fora de Portugal. O pardo nascido na Bahia e herói de guerra, Manuel Gonçalves Doria, cujo avô materno foi identificado como um mulato da Madeira, foi cuidadosamente pesquisado. ${ }^{22} \mathrm{O}$ outro era o africano Francisco da Mata Falcão, Capitão da Gente Preta do Reino de Angola, que foi mencionado diversas vezes na História Geral das Guerras Angolanas de António de Oliveira de Cadornega. ${ }^{23}$ Antes de se tornar cavaleiro da Ordem de Santiago, em 1648, Francisco precisou de diversas dispensas. Primeiro, D. João IV o dispensou do "defeito" de ser um mulato e permitiu que ele tivesse sua investigação de antecedentes feita em Lisboa em vez de Angola. Embora não se soubesse em que lugar da África tinham nascido sua mãe e seus avós maternos, testemunhas afirmaram que Francisco e a mãe eram considerados "Christãos velhos sem outra mistura". Entretanto, algumas testemunhas acharam que seus avós maternos eram gentios. O pai de Francisco era Antão da Mata Falcão, embora não esteja claro se Francisco era meio-irmão ou filho do médico da Corte, que tinha este mesmo nome. Francisco foi finalmente dispensado porque ele era um mulato nascido fora do casamento - um adulterino, já que o pai dele era casado - e seus avós maternos

\footnotetext{
${ }^{19}$ Ver carta de hábito, 20 de abril de 1608, ANTT, COC, livro 17, folios 385v-386.

${ }^{20}$ Ver "Lista dos Cavalleiros da Ordem de Christo," Biblioteca Nacional, Madri, libro 938, folio 137v.

${ }^{21}$ Para o acima, ver ANTT, COC, livro 9, folios 208 e 11.

${ }^{22}$ Dutra, "A Hard-Fought Struggle," p. 91-113.

${ }^{23}$ António de Oliveira de Cadornega, História Geral das Guerras Angolanas, [Lisboa, 1680] 3 vols. Lisboa, Agência Geral do Ultramar, 1942, vol. II, pp. 439, 589.
} 
eram pagãos ou gentios. ${ }^{24}$ De forma geral, o impedimento de ser descendente de gentios, embora listado nos Estatutos da Ordem junto com aqueles que eram descendentes de muçulmanos e judeus, não afetava a limpeza de sangue e, portanto, era uma dispensa relativamente fácil de receber do Rei.

Outro caso interessante foi o de João Cabral de Barros, Desembargador da Relação do Porto, cujas raízes estavam em Torres Vedras e Vila Real. Ele tinha servido brevemente no Brasil e estava sendo recompensado "por ter passado ao Maranhão para naquele Estado administrar justiça, no que mostrou muito zelo, e também em virtude das promessas que lhe fez o Conde de Odemira". ${ }^{25}$ Entretanto, suas provanças revelaram que seu avô materno tinha sido um comerciante e sua avó materna "fora negra e cativa" ${ }^{26}$ Depois de uma extensa investigação, a Mesa da Consciência e Ordens finalmente recomendou uma dispensa e ele recebeu sua carta de hábito da Ordem de Cristo em novembro de 1659. ${ }^{27}$

Outro caso que se estendeu entre o final do domínio Filipino e os primeiros tempos da Restauração Portuguesa foi o de Jacinto de Sampaio Costa, descrito como "filho de mulato". Numa portaria datada de 3 de março de 1640, ele foi identificado como "cavaleiro-fidalgo, filho natural de Pedro Valente da Costa" e estava sendo recompensado por seu serviço em Mazagão, Bahia, na Costa de França e por ter sido um prisioneiro em Argel. ${ }^{28}$ Seu caso foi apresentado à Mesa da Consciência e Ordens no final de 1640 e, depois de receber uma dispensa, sua carta de hábito foi emitida em $1642 .{ }^{29}$

${ }^{24}$ ANTT, Habilitações da Ordem de Santiago [citado daqui em diante como HOS], Letra F, maço 2, Número 46. Sua carta de hábito e alvará de cavaleiro são datados de 30 de dezembro e 23 de novembro de 1648, respectivamente. Ver Chancelaria da Ordem de Santiago [citada daqui em diante como COS], livro 15, fol. 175. Ver também Arquivo Histórico Ultramarino, códice 79, folios 143-143v e Inventário dos Livros das Portarias do Reino (citado daqui em diante como IPR) 2 vols. (Lisboa, Imprensa Nacional, 1909-1912)I, 18, 231. Resumo de Leitão Aranha encontra-se em BNL, CP, códice 156, folios 140v e 146.

${ }^{25}$ IPR II, 129.

${ }^{26}$ ANTT, HOC, Letra J, Maço 89, n. 1. Ver também BNL, CP, códice 156, folios 146v e 272.

${ }^{27}$ As cartas, datadas 26 de novembro de 1659, autorizando as cerimônias de outorga do título de cavaleiro encontram-se em ANTT, COC, livro 51, fols. 290-290v.

${ }^{28}$ Ver IPR I, 13, 14.

${ }^{29}$ Ver BNL, CP, códice 156, fol. 146v. As cartas autorizando as cerimônias de outorga do título de cavaleiro, datadas 22 de junho de 1642, encontram-se em ANTT, COC, livro 36, folios 196-196v. 
Muitos dos outros casos envolviam serviços prestados no norte da África ou na Ásia. No caso de Francisco Figueira da Costa, cujo pai mais cedo em sua carreira tinha trabalhado num forno em Mazagão no norte da África; o avô materno tinha sido cozinheiro dos jesuítas e mais tarde alfaiate; e a avó materna era mulata, os membros da Mesa da Consciência e Ordens observaram que o candidato tinha as características pessoais fundamentais (as "partes pessoais") e a necessária limpeza, mas que não tinha qualidade, devido aos impedimentos acima mencionados de seu pai e de seus avós maternos. ${ }^{30}$

Ele recebeu as dispensas necessárias em 1693 graças aos serviços militares de seu pai e seu tio em Mazagão. Não houve menção à sua avó mulata nas deliberações da Mesa. ${ }^{31}$ Um caso semelhante foi o de António Carvalho da Silva, identificado como cavaleiro fidalgo da Casa Real, que foi autorizado a ter as cerimônias de sagração de cavaleiro da Ordem de Cristo, realizadas em 1674 pelos dez anos de serviços militares em Tânger, lutando contra os muçulmanos. A investigação de antecedentes revelou que seu avô materno fora um lenhador (“cortador"), sua avó era mulata e seus avós paternos foram lavradores. A Mesa inicialmente se manifestou contra sua admissão e o Príncipe Regente concordou. Mas Carvalho apelou, alegando que, além dos serviços prestados no norte da África, havia lutado

alguns anos na Província do Alentejo e se achara na Batalha das Linhas de Elvas em que recebeo huma ferida na cabeça e na de Montes Claros em que matarão o cavalo e rendera hum sargento-mor. E que também servia de secretario do governo do Conde de Vale de Reis no Algarve sem ordenado, e de Apontador das obras da fortaleza do mesmo Reyno em que assistio com muito trabalho.

No dia 6 de fevereiro de 1674, a Mesa recomendou a dispensa e o rei a concedeu. Naquele ano Carvalho se tornou um cavaleiro da Ordem de Cristo. ${ }^{32}$

André Ferreira da Costa recebeu autorização para realizar as cerimônias de asseveração na Ordem de Cristo em 1710, por causa dos quarenta e dois anos de serviços do pai como "sargento mor pago." Mas a investigação de antecedentes revelou que o pai dele, Inácio Ferreira,

\footnotetext{
${ }^{30}$ ANTT, HOC, Letra F, Maço 34, n. 148; BNL, CP, códice 156, fol. 146-46v e 262.

${ }^{31}$ As cartas, datadas 30 de abril de 1672, autorizando as cerimônias de outorga do título de cavaleiro encontram-se em ANTT, COC, livro 63, fol. 42-42v.

32 ANTT, HOC, Letra A, Maço 48, n. 4. Ver também BNL, CP, códice 156, fol. 146 e 234v. Cartas, datadas 20 de abril de 1674, autorizando as cerimônias de outorga do título de cavaleiro encontram-se em ANTT, COC, livro 63, fol. 434v-435.
} 
foi barbeiro em seu princípio, mas depois alferes, capitão e sargento mor da comarca de Avis. Os avos paternos taverneiros e depois fazendeiros. O avô materno caboqueiro e hortelão e a avó materna vendadeira de hortaliça e filha de huma mulata captiva a quem depois se deu liberdade.

Mais ainda, André era bastardo, um "filho natural" (neste caso significando que os pais dele eram livres para casar, mas não tinham casado), e sua mãe era uma escrava mulata que mais tarde havia sido libertada pelo pai dele. André não teve dificuldades em conseguir a necessária dispensa. ${ }^{33}$

Diogo Fernandes Fogueira, tio de Manuel Fernandes Fogueira, mencionado anteriormente, que tinha uma excelente ficha militar na Índia, recebeu autorização para receber o título de cavaleiro da Ordem de Cristo em 1689. Nascido em Moura, ele tinha uma extensa folha de serviços prestados em Portugal, nas armadas e na Índia. Embora fosse cavaleiro fidalgo da Casa Real, ele precisava de uma dispensa por falta de qualidade por parte do seu pai e dos seus avós paternos, que haviam sido pastores e que ganhavam por dia como o próprio Diogo Fernandes Fogueira mais cedo em sua vida. Sua avó paterna tinha sido padeira. Mas a mãe de Diogo era mulata. Nas palavras da Mesa da Consciência e Ordens, sua mãe e seu avô paterno descendiam de mulatos porque sua bisavó era negra. Nesse caso, foi concedida uma dispensa pelo impedimento de falta de qualidade. ${ }^{34}$

Outro caso interessante foi o de João Veloso Cabral, que recebeu autorização para se tornar cavaleiro da Ordem de Cristo em 1707. Naquele ano, ele informou que havia servido vinte e um anos como soldado, sargento, alferes, ajudante, capitão de infantaria e, naquela época, sargento-mor das ordenanças e governador da cidade de Faro no Algarve. Mas em 1703, depois da investigação de antecedentes, a Mesa havia informado ao Rei que embora João Veloso Cabral tivesse as "partes pessoais" e "limpeza necessária," sua avó materna fora uma escrava. Seu pedido foi negado. Mas Veloso Cabral apelou e disse que as coisas eram um pouco mais complicadas do que isso, uma vez que seu bisavô, Ventura da Cunha, um cava-

\footnotetext{
${ }^{33}$ ANTT, HOC, Letra A, Maço 45, n. 68. A carta de hábito junto com o alvará de cavaleiro e o alvará de profissão, todos datados em 27 de julho de 1710, encontram-se em COC, livro 88, fol. 287-288. Ver também BNL, CP, códice 156, fol. 146 e $247 \mathrm{v}$.

${ }^{34}$ ANTT, HOC, Letra D, Maço 12, n. 38. Os serviços de Diogo também estão listados em Ibid., Letra M, Maço 41, n. 21. Ver também BNL, CP, códice 156, fol. 146 e 253. Para a carta de hábito, alvará de cavaleiro e alvará de profissão, todos datados 12 de dezembro de 1689, ver ANTT, COC, livro 49 , fol. $280-281$.
} 
leiro da Ordem de Cristo, tratava a avó materna de João como se ela fosse sua filha e que o tio avô materno de João, de quem herdara o nome, Deão da Sé do Algarve, chamava a avó materna de João Veloso Cabral de "sobrinha" e que ela era estimada pelas melhores pessoas da cidade de Faro. ${ }^{35}$

Percepções públicas reveladas no decorrer de algumas investigações de antecedentes tornam muitos desses casos difíceis de entender. João Carlos de Oliveira, que recebeu autorização para se tornar cavaleiro da Ordem de Santiago em 1693, é um bom exemplo disso. O título de cavaleiro de Santiago foi um dote, porque ele tinha se casado com Dona Francisca Ursula, a filha órfã de Manuel Simões de Sousa, nascido em Barreira, termo da vila de Tomar, que tinha prestado importantes serviços lutando contra os holandeses no Brasil. Seu irmão, Manuel de Sousa, recebeu um título de cavaleiro da Ordem de Cristo pelos serviços prestados pelo pai. Mas a investigação de antecedentes de João Carlos de Oliveira revelou que seu avô paterno havia sido dono de hospedaria e mulato; que seu avô materno fora dono de loja e que sua avó materna padeira. Além disso, não se sabia ao certo o local de nascimento dessa avó materna. Em resposta, João Carlos forneceu documentos legais de que seu avô paterno não era mulato. Ele declarou que "o impedimento de ser um mulato do qual ele foi acusado era tão falso que um homem que levantou semelhante calúnia contra o pai dele foi processado e ficou provado no tribunal que a acusação era falsa e que o pai dele não tinha esse 'defeito"'. Além do mais, "o caluniador foi condenado a pagar uma multa - uma sentença que foi confirmada pela Relação, como [Oliveira] provou com um affidavit, o que em termos legais assegurou que esta falsidade havia sido dissipada". ${ }^{36}$ Mas isso não pareceu importar muito - e a Mesa nunca esclareceu se o dono da hospedaria era mulato ou não, porque era a falta de qualidade que precisava de dispensa, e João Carlos de Oliveira a obteve. ${ }^{37}$

\footnotetext{
${ }^{35}$ ANTT, HOC, Letra J, Maço 93, n. 108. Sua carta de hábito, alvará de cavaleiro e alvará de profissão estão datados em 20 de março de 1707. Ver COC, livro 97, fol. 349-349v.

${ }^{36}$ Ver Francis A. Dutra, "Os Dotes dos Hábitos das Ordens Militares Portuguesas de Santiago e de Avis em Portugal e no Brasil no Século XVII," In: Maria Beatriz Nizza da Silva (ed.) Sexualidade, Família e Religião na Colonização do Brasil, Lisboa, Livros Horizonte, 2001, p. 170. Ver também ANTT, HOS, Letra J, maço 8, n. 29.

${ }^{37}$ Para o acima, ver também ANTT, HOS, Letra J, Maço 8, n. 29. Para a carta de hábito datada 18 de abril de 1693, ver ANTT, COS, livro 22, fol. 229. Para as cerimônias, ver ANTT, OS, livro 105, fol. 81v. Os resumos de Leitão Aranha encontram-se em BNL,CP, códice 156, fol. 146v e 272.
} 
Relacionado a esse foi o caso de José Pereira da Mota, que tinha servido como fiscal da Coroa e que finalmente recebera autorização para obter o título de cavaleiro da Ordem de Cristo em 1697. Nas provanças "constara que seu Pai foi olheiro da porta da fruta nesta cidade (de Lisboa), seu Avô paterno cozinheiro, seu Avô materno carcereiro e sua avó materna mulata." O título de cavaleiro estava sendo concedido pelos serviços prestados pelo sargento-mor de Setúbal, Domingos de Carrião, tio da esposa de José, e pelos do pai dele. O fato de sua avó materna ser mulata não entrou em discussão. A questão era se ser inspetor de frutas nas Portas de Santo Antão era uma ocupação artesanal, e o mesmo com relação a ser carcereiro. O avô materno tinha sido carcereiro na prisão de Avis. Argumentou-se, finalmente, que ser carcereiro não era uma ocupação artesanal, e que ocupações similares não acrescentavam nem retiravam nobreza. José Pereira da Mota também pôde fazer o jogo da pureza de sangue ao dizer que se não conseguisse dispensa seu crédito estaria arruinado porque a recusa iria ser considerada prova de que ele tinha ascendência judia. Os deputados ficaram muito divididos, mas finalmente o Rei concedeu dispensa a José Pereira da Mota com a condição de que ele conseguisse três marinheiros para a armada da Coroa ou para os navios que estavam de partida para a Índia. O fato de sua avó materna ter sido mulata não parece ter afetado a decisão. ${ }^{38}$

Mais ou menos por esta época, outro burocrata da Coroa, Sebastião de Freitas de Macedo, também recebeu um título de cavaleiro da Ordem de Cristo, porque havia servido como "Praticante do Número dos Contos de Reino e Casa" e por causa dos serviços prestados por seu sogro, alguns deles na Índia. Em 1689, a Mesa relatou que pelas provanças "constou que em sua pessoa concorrem as partes pessoais que se requerem porém que lhe falta a qualidade por seu pai e avô paterno averem sido singeleiros, lavrando em terra alheas por jornal, e que o mesmo avô era mulato, filho de huma negra". ${ }^{39}$ Embora a maioria dos membros da Mesa recomendassem a dispensa, o Doutor Martim Monteiro Paim expressou desagrado com relação a "mecânica tão baixa como a de ser bisneto de huma

\footnotetext{
${ }^{38}$ ANTT, HOC, Letra J, Maço 98, n. 35. Sua carta de hábito, alvará de cavaleiro e alvará de profissão estão datados 20 de junho de 1697. Ver COC, livro 83, folios 2-2v. O resumo de Leitão Aranha encontra-se em BNL, CP, códice 156, folios 146v, 229 e 281v.

${ }^{39}$ ANTT, HOC, Letra S, Maço 6, n. 38. Ver também BNL, CP, códice 156, folios 147v e 311v.
} 
negra, e seu pai e avô paterno lavradores de jornal". Entretanto, no dia 25 de fevereiro de 1690, Sebatião recebeu sua carta de hábito na Ordem de Cristo. ${ }^{40}$

Em 1700, Manuel Garcia Cardoso foi agraciado com o título de cavaleiro da Ordem de Cristo. Filho de outro Manuel Garcia Cardoso, ele nasceu na vila de Alter do Chão. Descrito como um "escudeiro e cavaleiro da Casa Real", ele tinha uma longa lista de serviços prestados no sul da Ásia. A investigação de antecedentes revelou que, embora Manuel tivesse as necessárias características pessoais (partes pessoais) e pureza de sangue, sua avó paterna era mulata. "Provanças constou que em sua pessoa concorrem as partes pessoais e limpeza necessária, mas por também constar que sua avó paterna foi mulata." Os membros da Mesa inicialmente se manifestaram contra a admissão, e Pedro II concordou. Mas Manuel apelou dizendo que o título de cavaleiro foi concedido por serviços prestados "nas armadas e fortalezas do Estado da Índia”. No ano seguinte, a Mesa recomendou a dispensa e o Rei concordou. ${ }^{41}$

Em 1712, José Freire de Andrade, cuja avó tinha sido uma escrava, recebeu autorização para se tornar cavaleiro da Ordem de Cristo depois de uma dispensa concedida no início daquele mesmo ano por causa dos serviços prestados por seu pai e por seus próprios serviços militares. ${ }^{42}$

Sete anos depois, em 1719, João de Sá Vilhena recebeu autorização para se tornar cavaleiro da Ordem de Cristo embora tivesse sido revelado "que sua Mai foi lavandeira, o Avô paterno sapateiro, e o materno descendente de mulato e homem que servia em todo o trabalho por jornal." João de Sá de Vilhena na época de concessão do título estava servindo no posto de coronel de infantaria reformado e tinha participado da Guerra de Sucessão Espanhola. A Mesa relatou que a investigação de antecedentes tinha revelado que ele possuía as "partes pessoais e limpeza necessária”, apesar dos impedimentos mencionados acima. Mais tarde ele foi dispensado. ${ }^{43}$

\footnotetext{
${ }^{40}$ ANTT, COC, livro 49, folios 316v-319.

${ }^{41}$ ANTT, HOC, Letra M, maço 42, n. 33. Ver também BNL, CP, códice 156, folio 147. Cartas, datadas em 23 de janeiro 1702, autorizando as cerimônias de outorga do título de cavaleiro encontram-se em ANTT, COC, livro 74, folios 350-350V.

${ }^{42}$ BNL, CP, códice 156, folio 146V. Sua carta de hábito, alvará de cavaleiro e alvará de profissão são datados 11 de agosto de 1712. Ver ANTT, COC, livro 102, folios 335-336.

${ }^{43}$ ANTT, HOC, Letra J, maço 93, n. 35. Carta de hábito, alvará de cavaleiro e alvará de profissão estão datados 3 de março de 1719. Ver COC, livro 98, folios 226-227. Ver também BNL, CP, códice 156, folios $146 \mathrm{v}$ e 227.
} 
Naquele mesmo ano de 1719, Manuel Monis, que havia servido mais de treze anos na Índia, tinha alcançado o posto de capitão-tenente e recebido um título de cavaleiro da Ordem de Cristo do Vice-Rei, Vasco Fernandes César de Meneses (mais tarde primeiro conde de Sabugosa). Suas provanças revelaram que

em sua pessoa concorrem as partes pessoais e limpeza necessaria. Porém que o mesmo justificante foi alfaiate em seu princípio e depois passou para o Estado da Índia. O pai e avô paterno Alvaneos, e que a avó paterna tem defeito de mulatícia tanto que o pai do Justificante foi Juis em huma Irmandade em que só servem pretos e por tambem não constar com total clareza das naturalidades do Avós maternos nem de sua qualidade. ${ }^{44}$

Originalmente, a entrada de Manuel foi negada, mas por causa dos "serviços grandes na Índia militares e próprios”, ele mais tarde recebeu sua carta de hábito em 10 de março de $1719 .{ }^{45}$

Mas Manuel Coelho da Franca ou Franco não conseguiu obter dispensa. Sua investigação de antecedentes revelou que ele era "mulato notoriamente", tinha mais de cinquenta anos, que, mais cedo em sua vida, foi um requerente; seu pai era professor e "pessoa de segunda condição"; e que sua mãe era uma mulher humilde. Mas a evidência mais danosa foi a reputação de ser um Cristão-Novo "com fama antiga, constante e permanente pela via paterna, declarando algumas testemunhas ter também na mesma forma pela via materna”. Em 7 de janeiro de 1723, a Mesa relatou seus achados para o Rei, que respondeu: "Obedeçam os Estatutos." ${ }^{46}$ Como mostra este estudo, com base nos registros das ordens militares portuguesas, que eram as guardiãs da "limpeza de sangue" em Portugal, havia uma grande diferença entre não possuir pureza de sangue e não possuir "qualidade".

\footnotetext{
${ }^{44}$ ANTT, HOC, Letra M, maço 43, n. 91. Ver também BNL, CP, códice 156, folios 147, 190 e 297.

${ }^{45}$ ANTT, COC, livro 98, folios 248v-249.

${ }^{46}$ ANTT, HOC, Letra M, maço 40, n. 30. Ver também BNL, CP, códice 156, folios 107, 108v e 147v.
} 